\title{
Optimization of Inter-industry Carbon Emission Transfer Structure Based on Decoupling Effects: an empirical analysis from Chinese industry
}

\author{
Licheng Sun ${ }^{1 *}$, Lingling Jiang ${ }^{1}$,Biying Zhao ${ }^{2}$ \\ ${ }^{1}$ School of Management, Jiangsu University, No. 301 Xuefu Road, Zhenjiang 212013, China \\ ${ }^{2}$ School of Environment and Safety engineering, Jiangsu University, No. 301 Xuefu Road, Zhenjiang 212013, China
}

\begin{abstract}
This paper utilizes 27 Chinese industry sectors as study objects, and measures the decoupling effects of the industrial carbon emission transfer; furthermore, this paper proposes several optimizing strategies for an inter-industry carbon emission transfer structure toward the realization of dual goals, i.e., industrial economic development and industrial carbon emission reduction. The research result shows that: (1)Different industries show different decoupling effects of carbon emission transfer, and the distribution of the six states of decoupling effects could all be observed.(2) With respect to dynamic variations, the decoupling effects of industrial carbon emission transfer were optimal during the late stage, and the decoupling effects during 2010-2012 were the most optimal.(3) With respect to the optimizing strategies for the inter-industry carbon emission transfer, efforts should be focused on increasing the carbon emission exports, while reducing the carbon emission imports of 11 industries (CMWI and others). Future efforts should be directed at increasing carbon emission imports and reducing carbon emission exports in the three industries of CLII, PPSM, and MPI, while increasing both carbon emission exports and imports in 10 industries (FMTP and others), and reducing both carbon emission imports and exports in the three industries of MMII, OMW, and WRT.
\end{abstract}

\section{Introduction}

Given that industry sectors constitute the backbone of the Chinese national economy, the realization of overall carbon emission reduction goals in a particular region mainly relies on the successful completion of carbon emission reduction goals of various industry sectors in this region. Therefore, promoting the low-carbon development of regional industry sectors is of vital importance in the current emission reduction environment.

To explore the path of low-carbon industrial development, numerous scholars have adopted decoupling analyses to investigate the relationship between industrial economic development and industrial carbon emission. For instance, OECD (2002) defined the inner connotation decoupling. Herry $(2003)^{[1]}$ examined decoupling effect of the transportation industry for Europe and the transportation industry of Finland during 1970-2001. Tapio (2005) ${ }^{[2]}$ referred to as the Tapio decoupling index system, has been extensively applied in studies on the decoupling of the relationship between economic growth and the environment, carbon emission, etc. Then, $\mathrm{Lu}$ et al. (2007) ${ }^{[3]}$, Zhao et al. (2016) ${ }^{[4]}$ etc. analyzed the decoupling effects of Germany, Japan, South Korea, and China from different perspectives.

In summary, the above studies mainly present the following shortcoming: first, neither have all industry sectors been investigated as a whole, nor have they horizontally analyzed the differences in the decoupling effects of various industries. Second, the influence of inter-industry carbon emission transfer has not been taken into account. Third, existing studies have not analyzed the relationship between industrial economic development and industrial carbon emission from the perspective of industrial structure optimization, nor have they explored optimizing strategies for the industrial carbon emission transfer structure faced by the dual restrictions of industrial economic development and industrial carbon emission reduction.

This paper further measures the carbon emission imports volume and exports volume of each industry sector; after that, it mainly analyzes the decoupling effects of the industrial carbon emission imports and exports; from the perspective of dual restrictions by industrial economic development and industrial carbon emission reduction, this paper conducts an in-depth analysis of the structural relationship of inter-industry carbon emission transfer and refines the optimizing strategies for inter-industry carbon emission transfer.

\footnotetext{
*Corresponding author. E-mail address:sunsee213@ujs.edu.cn(Licheng Sun). Tel: +86 15850455868
} 


\section{Model Construction}

\subsection{Measurement model for industrial carbon emission transfer}

This paper mainly adopts the input-output model to construct a measurement model for inter-industry carbon emission transfer; the basic formulas are given in Formulas (1)-(3) (Leontief,1970) ${ }^{[5]}$ :

$$
\mathrm{AX}+\mathrm{Y}=\mathrm{X}
$$

Formula (1) can also be expressed as:

$$
X=(I-A)^{-1} Y
$$

where $X$ represents the total output; I represents the unit matrix; $A$ represents the direct consumption coefficient matrix; $(I-A)^{-1}$ represents the Leontief inverse matrix; Y represents the final demand.

$$
\alpha_{\mathrm{pk}}=\frac{\mathrm{z}_{\mathrm{pk}}}{\mathrm{x}_{\mathrm{k}}}(\mathrm{p}, \mathrm{k}=1,2,3, \cdots, \mathrm{n})
$$

$\mathrm{a}_{\mathrm{pk}}$ represents the direct consumption coefficient; $\mathrm{z}_{\mathrm{pk}}$ represents the value quantity of the products or services of industry sector $\mathrm{p} ; \mathrm{x}_{\mathrm{k}}$ represents the total output of the industry sector $\mathrm{k}$.

It can be seen horizontally from the input-output table, $Y$ is constituted of the final demand $Y_{d d}$ and the export volume $Y_{e e}$ of relevant industry sectors, i.e.:

$$
\mathrm{Y}=\mathrm{Y}_{\mathrm{dd}}+\mathrm{Y}_{\mathrm{ee}}
$$

Assuming that $\mathrm{EF}_{\mathrm{ee}}$ represents a matrix constituted by the $\mathrm{CO}_{2}$ emission intensities of various industry sectors in the horizontal direction, the $\mathrm{CO}_{2}$ emission of these industry sectors can be obtained via Formula (2):

$$
\mathrm{C}=\mathrm{EF}_{\mathrm{ee}}\left(\mathrm{I}-\mathrm{A}_{\mathrm{ee}}\right)^{-1}\left(\mathrm{Y}_{\mathrm{dd}}+\mathrm{Y}_{\mathrm{ee}}\right)
$$

$\mathrm{A}_{\text {ee }}$ represents the direct consumption matrix of industry sectors in the horizontal direction. Based on the connotation of industrial carbon emission exports (Sun, 2017) ${ }^{[6]}$, we can obtain the carbon emission exports volume $\mathrm{C}_{\mathrm{ee}}$ for each industry sector $\left(\mathrm{Su}, 2010^{[7]}\right.$; Sun, $\left.2016^{[8]}\right)$.

$$
\mathrm{C}_{\mathrm{ee}}=\mathrm{EF}_{\mathrm{ee}}\left(\mathrm{I}-\mathrm{A}_{\mathrm{ee}}\right)^{-1} \mathrm{Y}_{\mathrm{ee}}
$$

Similarly, the carbon emission imports volume $\mathrm{C}_{\mathrm{e}}$ can be obtained for each industry sector.

$$
\mathrm{C}_{\mathrm{ei}}=\mathrm{EF}_{\mathrm{ei}}\left(\mathrm{I}-\mathrm{A}_{\mathrm{ei}}\right)^{-1} \mathrm{Y}_{\mathrm{ei}}
$$

where, $\mathrm{EF}_{\mathrm{ei}}, \mathrm{A}_{\mathrm{ei}}$, and $\mathrm{Y}_{\mathrm{ei}}$ represent the carbon emission intensity matrix, the direct consumption matrix, and the import vector matrix of vertical industry sectors, respectively. The specific value of the carbon emission intensity EF of each industry sector can be calculated with the following formula:

$$
\mathrm{ef}_{\mathrm{k}}=\sum_{\mathrm{j}=1}^{\mathrm{m}} \beta_{\mathrm{kj}} \mathrm{q}_{\mathrm{kj}} / \mathrm{x}_{\mathrm{k}}
$$

where $\mathrm{ef}_{\mathrm{k}}$ represents the carbon emission intensity of industry sector $\mathrm{k} ; \mathrm{q}_{\mathrm{kj}}$ represents the $\mathrm{j}^{\text {th }}$ type of resources consumed by industry sector $\mathrm{k}$ during the production process of products and services; $\beta_{\mathrm{kj}}$ represents the carbon emission coefficient of the $j^{\text {th }}$ type of resources (IPCC, 2006); $\mathrm{x}_{\mathrm{k}}$ represents the output value increase of industry sector $\mathrm{k}$.

\subsection{Measurement model for the decoupling effects of industrial carbon emission transfer}

The decoupling model described by Tapio (2005) ${ }^{[2]}$ was adopted as basis to construct a measurement model for the decoupling effects of inter-industry carbon emission transfer. The specific model is below:

$$
\mathrm{r}_{\mathrm{gk}}=\frac{\Delta \mathrm{C}_{\mathrm{gk}} / \mathrm{C}_{\mathrm{gk}}}{\Delta \mathrm{Y}_{\mathrm{k}} / \mathrm{Y}_{\mathrm{k}}}
$$

where $g$ represents the industrial carbon emission imports or exports; $r_{\mathrm{gk}}$ represents the decoupling elasticity coefficient of carbon emission imports or exports of the industry sector $\mathrm{k} ; \mathrm{C}_{\mathrm{gk}}$ represents the carbon emission imports or exports volume of the industry sector $\mathrm{k}$ during the base period; $\Delta \mathrm{C}_{\mathrm{gk}}$ represents the variation of the carbon emission imports or exports of the industry sector $\mathrm{k}$ in the report period relative to the base period; $Y_{k}$ represents the output value increase of the industry sector $\mathrm{k}$ during the base period; $\Delta \mathrm{Y}_{\mathrm{k}}$ represents the variation of the output value increase of the industry sector $\mathrm{k}$ during the report period relative to the base period.

Based on the decoupling elasticity coefficient of industrial carbon emission transfer and in combination with the study conclusions drawn by Feng and Wang (2015) ${ }^{[9]}$, this paper classifies the decoupling effects of industrial carbon emission transfer into six types, i.e., strong decoupling, weak decoupling, expansive negative decoupling, strong negative decoupling, weak negative decoupling, and recessive decoupling.

\section{Industry Selection and Data Sources}

To achieve comparability of the results, this paper uses the industry sector structure of the input-output table of 2012 as basis, reconsolidates and abridges the industry sectors of the input-output tables of $2002 / 2005 / 2007 / 2010$, and ultimately adopts 27 industry sectors as study objects.

According to the classification of Chinese industry sectors suggested by Guo (2010) ${ }^{[10]}$, this paper classifies these 27 industry sectors into five types, as detailed in Table. 1. All relevant data of this paper originate from the input-output tables of various year. The output value increases of various industry sectors all originate from the China Statistical Yearbooks of various years; the total energy consumption (standard coal) of each industry originates from the China Energy Statistical Yearbooks of various years. 
Table. 1 Selection and classification of industry sectors

\begin{tabular}{|c|c|c|c|c|c|c|c|}
\hline No. & $\begin{array}{l}\text { Industry } \\
\text { sector type }\end{array}$ & Industry sector & $\begin{array}{c}\text { Abbre } \\
\text { v. }\end{array}$ & $\begin{array}{l}\mathbf{N} \\
\mathbf{0}\end{array}$ & $\begin{array}{l}\text { Industry } \\
\text { sector } \\
\text { type }\end{array}$ & Industry sector & Abbrev. \\
\hline 1 & \multirow{5}{*}{$\begin{array}{l}\text { Energy } \\
\text { industry } \\
\text { sector } \\
\text { (5) }\end{array}$} & $\begin{array}{l}\text { Coal Mining and Washing } \\
\text { Industry }\end{array}$ & $C M W I$ & 15 & \multirow{5}{*}{$\begin{array}{l}\text { Heavy } \\
\text { industry } \\
\text { sector } \\
\text { (9) }\end{array}$} & $\begin{array}{l}\text { General/Special } \\
\text { Manufacturing }\end{array}$ & GSEM \\
\hline 2 & & Oil and Gas Extraction & $O G E$ & 16 & & $\begin{array}{l}\text { Transport Equipment } \\
\text { Manufacturing Industry }\end{array}$ & TEMI \\
\hline 3 & & $\begin{array}{l}\text { Petroleum Processing, Coking } \\
\text { Products and Nuclear Fuel } \\
\text { Processing }\end{array}$ & $P P C N$ & 17 & & $\begin{array}{l}\text { Electrical Machinery and Equipment } \\
\text { Manufacturing }\end{array}$ & EMEM \\
\hline 4 & & $\begin{array}{l}\text { Production \& Supply of Electric } \\
\text { Power and Heating Power }\end{array}$ & EHPS & 18 & & $\begin{array}{l}\text { Communication Equipment, } \\
\text { Computer and Other Electronic } \\
\text { Equipment Manufacturing }\end{array}$ & $C E C E$ \\
\hline 5 & & $\begin{array}{l}\text { Gas Production and Supply } \\
\text { Industry }\end{array}$ & GPSI & 19 & & $\begin{array}{l}\text { Machinery Manufacturing Industry } \\
\text { for Instruments, Meters, Culture and } \\
\text { Office }\end{array}$ & $M M I I$ \\
\hline 6 & \multirow{5}{*}{$\begin{array}{l}\text { Light } \\
\text { industry } \\
\text { sector } \\
\text { (5) }\end{array}$} & $\begin{array}{l}\text { Food Manufacturing and } \\
\text { Tobacco Products }\end{array}$ & FMTP & 20 & \multirow{5}{*}{$\begin{array}{l}\text { Other } \\
\text { industry } \\
\text { sectors } \\
\text { (4) }\end{array}$} & $\begin{array}{l}\begin{array}{l}\text { Metals Mining and Dressing } \\
\text { Industry }\end{array}\end{array}$ & $M M I$ \\
\hline 7 & & Textile Industry & $T I$ & 21 & & $\begin{array}{l}\text { Non-metal Minerals Mining and } \\
\text { Dressing Industry }\end{array}$ & $N M M I$ \\
\hline 8 & & $\begin{array}{l}\text { Clothing, Leather, Down and } \\
\text { Products Industry }\end{array}$ & CLII & 22 & & Other Manufacturing and Wastes & $O M W$ \\
\hline 9 & & $\begin{array}{l}\text { Wood Processing and Furniture } \\
\text { Manufacturing }\end{array}$ & WPFM & 23 & & $\begin{array}{l}\text { Water Production and Supply } \\
\text { Industry }\end{array}$ & WPSI \\
\hline 10 & & $\begin{array}{l}\text { Papermaking, Printing and } \\
\text { Stationary Manufacturing }\end{array}$ & PPSM & 24 & & Construction Industry & CTI \\
\hline 11 & \multirow{4}{*}{$\begin{array}{l}\text { Heavy } \\
\text { industry } \\
\text { sector } \\
\text { (9) }\end{array}$} & Chemical Industry & $C I$ & 25 & \multirow{3}{*}{$\begin{array}{l}\text { Service } \\
\text { industry } \\
\text { sector } \\
\text { (4) }\end{array}$} & Transportation and Warehousing & $T W$ \\
\hline 12 & & Non-metal Mineral Products & NMMP & 26 & & Wholesale and Retail Trade & $W R T$ \\
\hline 13 & & $\begin{array}{l}\text { Metal Smelting and Rolling } \\
\text { Processing }\end{array}$ & MSRP & 27 & & Accommodation and Catering & $A C$ \\
\hline 14 & & Metal Products Industry & MPI & 28 & & & \\
\hline
\end{tabular}

\section{Empirical analysis}

\subsection{Analysis of the decoupling effects of industrial carbon emission transfer}

Adopting 2002 as base period and 2012 as report period, Formulas (6), (7), and (9) can be used to calculate the decoupling effect states of the overall industrial carbon emission transfer and their dynamic variation trends for 2002-2012, as detailed in Table. 2.

As shown in Table. 2, for the energy industry and the heavy manufacturing industry, the decoupling effects of carbon emission transfer mainly presented the state of expansive negative decoupling and the weak decoupling, respectively. The decoupling state of carbon emission exports in the energy industry was weak; for the light manufacturing industry, the decoupling state of carbon emission transfer was predominantly weak; for the service industry sector and other industry sectors, the distribution of the three states of expansive negative decoupling, weak decoupling, and strong decoupling could all be observed.

As for the dynamic variation trends ,the decoupling effects of industrial carbon emission transfer were more significant during the late stage and the decoupling effects of 2010-2012 were optimal, the number of industries showing a strong decoupling state in industrial carbon emission exports increased from six in 2005-2007 to 20 in 2010-2012; the number of industries showing a strong decoupling state in industrial carbon emission imports increased from three to 13 during the same timeframe.

These results indicate that, due to the acceleration of economic transformation, the technological level of these industries presented an increasing trend that has driven their relatively rapid development; on the other hand, the growth rate of the $\mathrm{CO}_{2}$ emission transfer showed a trend of slowing down relative to the growth rate of GDP. In particular, after 2007, the state started to emphasize $\mathrm{CO}_{2}$ emission reduction, and proposed to realize the development goals of energy conservation and emission reduction, while increasing the supply of clean energies. This further promoted the transition of the decoupling effects of industrial carbon emission transfer into a strong decoupling state during 2010-2012; moreover, with the passage of time, the number of industries showing an expansive negative decoupling state in carbon emission transfer decreased during both cases (exports and imports).However, during 2010-2012, few industries experienced an economic recession. For instance, in MMII, OMW, and WRT, the decoupling effects of carbon emission transfer were uniformly in the "recessive decoupling" and "strong negative decoupling" states. 
Table. 2 Variations in the decoupling effects of industrial carbon emission transfer

\begin{tabular}{|c|c|c|c|c|c|c|c|c|c|c|c|c|}
\hline \multirow{3}{*}{$\begin{array}{c}\text { Industr } \\
\mathrm{y}\end{array}$} & \multicolumn{6}{|c|}{ Carbon emission exports } & \multicolumn{6}{|c|}{ Carbon emission imports } \\
\hline & \multicolumn{2}{|c|}{ 2005-2007 } & \multicolumn{2}{|c|}{ 2007-2010 } & \multicolumn{2}{|c|}{ 2010-2012 } & \multicolumn{2}{|c|}{ 2005-2007 } & \multicolumn{2}{|c|}{$2007-2010$} & \multicolumn{2}{|c|}{$2010-2012$} \\
\hline & $\begin{array}{c}\text { Decoupl } \\
\text { ing } \\
\text { value } \\
\end{array}$ & $\begin{array}{l}\text { Decoupl } \\
\text { ing type }\end{array}$ & $\begin{array}{c}\text { Decoupl } \\
\text { ing } \\
\text { value } \\
\end{array}$ & $\begin{array}{l}\text { Decoupl } \\
\text { ing type }\end{array}$ & $\begin{array}{c}\text { Decoupl } \\
\text { ing } \\
\text { value } \\
\end{array}$ & $\begin{array}{l}\text { Decoupl } \\
\text { ing type }\end{array}$ & $\begin{array}{c}\text { Decoupl } \\
\text { ing } \\
\text { value } \\
\end{array}$ & $\begin{array}{l}\text { Decoupl } \\
\text { ing type }\end{array}$ & $\begin{array}{c}\text { Decoupl } \\
\text { ing } \\
\text { value } \\
\end{array}$ & $\begin{array}{l}\text { Decoupl } \\
\text { ing type }\end{array}$ & $\begin{array}{c}\text { Decoupl } \\
\text { ing } \\
\text { value } \\
\end{array}$ & $\begin{array}{l}\text { Decoupl } \\
\text { ing type }\end{array}$ \\
\hline CMWI & -0.30 & 1 & 0.47 & 2 & -1.22 & 1 & 0.25 & 2 & 0.77 & 2 & 0.63 & 2 \\
\hline OGE & 2.44 & 3 & 0.29 & 2 & -3.80 & 1 & 1.07 & 3 & 1.95 & 3 & 1.98 & 3 \\
\hline MMI & 0.45 & 2 & 0.70 & 2 & -1.29 & 1 & 0.55 & 2 & 0.02 & 2 & 0.36 & 2 \\
\hline NMMI & 0.23 & 2 & 1.61 & 3 & -0.31 & 1 & -0.13 & 1 & 1.76 & 3 & 0.54 & 2 \\
\hline FMTP & 0.58 & 2 & 0.80 & 2 & -0.44 & 1 & 2.09 & 3 & 0.43 & 2 & -0.45 & 1 \\
\hline TI & 0.70 & 2 & -0.11 & 1 & -7.42 & 1 & 1.14 & 3 & 0.25 & 2 & 10.74 & 3 \\
\hline CLII & 1.20 & 3 & 0.31 & 2 & 0.18 & 2 & 4.47 & 3 & 2.63 & 3 & -1.12 & 1 \\
\hline $\begin{array}{c}\text { WPF } \\
\text { M }\end{array}$ & 0.44 & 2 & 2.13 & 3 & -0.44 & 1 & 0.31 & 2 & 8.14 & 3 & -0.57 & 1 \\
\hline PPSM & 0.27 & 2 & 0.88 & 2 & 0.49 & 2 & 1.02 & 3 & 1.88 & 3 & -0.89 & 1 \\
\hline $\mathrm{PPCN}$ & 0.95 & 2 & 0.34 & 2 & -0.07 & 1 & 0.38 & 2 & 0.18 & 2 & -0.44 & 1 \\
\hline CI & 0.79 & 2 & 0.66 & 2 & -0.42 & 1 & 0.61 & 2 & 0.30 & 2 & 0.15 & 2 \\
\hline $\begin{array}{l}\text { NM } \\
\text { MP }\end{array}$ & 0.10 & 2 & 1.47 & 3 & -0.45 & 1 & 0.45 & 2 & 0.99 & 2 & -0.16 & 1 \\
\hline MSRP & 0.55 & 2 & 1.39 & 3 & -0.38 & 1 & 0.29 & 2 & 1.67 & 3 & -0.26 & 1 \\
\hline MPI & 0.48 & 2 & 0.82 & 2 & 0.09 & 2 & 0.77 & 2 & 2.58 & 3 & -0.79 & 1 \\
\hline GSEM & 0.19 & 2 & 0.86 & 2 & -1.57 & 1 & 1.57 & 3 & 0.43 & 2 & -2.75 & 1 \\
\hline YEMI & 0.49 & 2 & 0.65 & 2 & -0.80 & 1 & 0.22 & 2 & 0.23 & 2 & -2.55 & 1 \\
\hline $\begin{array}{c}\text { EME } \\
\text { M }\end{array}$ & 1.09 & 3 & 0.73 & 2 & -0.98 & 1 & 1.13 & 3 & 0.28 & 2 & -0.42 & 1 \\
\hline CECE & -0.05 & 1 & 1.03 & 3 & -0.71 & 1 & 1.82 & 3 & 1.16 & 3 & 0.15 & 2 \\
\hline MMII & -0.38 & 1 & 0.45 & 2 & 2.42 & 4 & 4.45 & 3 & 0.59 & 2 & -1.80 & 5 \\
\hline OMW & 0.16 & 2 & 0.69 & 2 & 1.72 & 4 & -0.15 & 1 & 2.30 & 3 & -7.23 & 5 \\
\hline EHPS & -0.86 & 1 & 1.27 & 3 & -0.77 & 1 & 1.01 & 3 & 1.84 & 3 & 0.23 & 2 \\
\hline GPSI & 0.05 & 2 & 0.61 & 2 & -0.22 & 1 & 8.98 & 3 & -0.41 & 1 & -0.99 & 1 \\
\hline WPSI & -0.47 & 1 & 0.99 & 2 & -22.56 & 1 & 2.12 & 3 & -0.38 & 1 & 15.76 & 3 \\
\hline CTI & 1.34 & 3 & 0.38 & 2 & 0.17 & 2 & -1.02 & 1 & 0.18 & 2 & 4.61 & 3 \\
\hline TW & 0.19 & 2 & 1.01 & 3 & -0.49 & 1 & 0.74 & 2 & 1.95 & 3 & -0.39 & 1 \\
\hline WRT & 1.52 & 3 & -0.15 & 1 & -8.53 & 5 & 1.11 & 3 & 0.14 & 2 & -6.20 & 5 \\
\hline $\mathrm{AC}$ & -0.06 & 1 & 0.35 & 2 & -1.79 & 1 & 1.38 & 3 & 0.50 & 2 & 0.56 & 2 \\
\hline
\end{tabular}

Note: In the "Decoupling type" columns, "1-5" represent "strong decoupling", "weak decoupling", "expansive negative decoupling", "recessive decoupling" and "strong negative decoupling", respectively.

\subsection{Optimizing strategies for the inter-industry carbon emission transfer structure}

To improve the economic output capacity of the inter-industry carbon emission transfer, this part adopts the decoupling state of 2010-2012 as benchmark and, based on the above analysis of the decoupling effects of industrial carbon emission transfer, it proposes four optimizing strategies for the inter-industry carbon emission transfer structure.

Firstly, the decoupling effects of carbon emission exports were predominantly strong in 11 industries (CMWI and others), while they were only weak in CTI. This indicated that these 11 industries, with their increasing carbon emission exports volume, would not only accelerate economic growth, but would also witness a further decline in the pressure of reducing carbon emission, due to their economic growth. In these 11 industries, the decoupling effects of carbon emission imports were dominated by both the weak decoupling state and the expansive negative decoupling state; this suggests that moderately reducing carbon emission imports in these industries could facilitate their economic growth. Therefore, to better increase the economic output of these 11 industries, efforts should be directed toward optimizing their industrial carbon emission transfer structure by increasing the carbon emission exports, while decreasing industrial carbon emission imports.

Secondly, in the three industries of CLII, PPSM, and MPI, the decoupling effects of carbon emission imports uniformly presented a strong decoupling state, while the decoupling effects of carbon emission exports uniformly presented a weak decoupling state. This result indicates that, in these three industries, the decoupling effects of carbon emission imports exceeded those of carbon emission exports. As indicated by the countermeasures, efforts should be made to increase carbon emission 
imports and decrease carbon emission exports in all of these three industries. Various industries should stress the introduction of products consumed by them from the outside, reduce the production of intermediate products by them, follow the principle of simultaneous promotion of "producer responsibility system" and "consumer responsibility system", and should shoulder their share of the obligation to reduce the carbon emission.

Thirdly, it contains a total of ten industries (FMTP and others), in which the decoupling effects of carbon emission exports and imports uniformly presented a strong decoupling state. This indicated that both the economic development capacity and the emission reduction capacity of carbon emission transfer in these industries were all relatively good, and that, on the whole, substantial support should be directed to the development of these industries, to promote the effective realization of the dual goals of industrial economic development and emission reduction. With regard to the optimizing strategies for transfer structure, both the carbon emission exports volume and the imports volume should be increased in these 10 industries. With regard to the specific coefficients, in FMTP, WPFM, PPCN, GSEM, TEMI, and GPSI, the decoupling degree of carbon emission imports exceeded that of carbon emission exports; in NMMP, MSRP, EMEM, and TW, the opposite was the case. Thus, in the six industries in which the growth rate of carbon emission imports exceeded that of carbon emission exports, the optimization of industrial carbon emission transfer structure should better be promoted; in NMMP, MSRP, EMEM, and TW, the opposite was the case as well.

Fourthly, As for MMII, OMW, and WRT, the decoupling effects of carbon emission exports and imports showed states of "recessive decoupling" and "strong negative decoupling", the latter of which played the dominant role. This indicated that these three industries experienced a negative growth of industrial economy, growth of carbon emission transfer, and thus, the possibility of further increased environmental pressure. With regard to these three industries, to realize the dual goals of industrial economic development and emission reduction, it is necessary to simultaneously reduce the carbon emission exports volume and carbon emission imports volume

\section{Conclusions and policy implication}

Through investigating the decoupling effects of the industrial carbon emission exports and imports from the industrial economic development of China during 2002-2012, its main conclusions and policy suggestions are summarized in the following:

(1)On the whole, the decoupling effects of industrial carbon emission transfer in China during 2002-2012 were predominantly weak and the decoupling effects of the industrial carbon emission exports exceeded those of the carbon emission imports. This suggests that the growth rate of carbon emission transfer is lower than that of output value for most of the Chinese industries, that the economic elasticity of industrial carbon emission transfer is reasonable, and that the economic spillover benefits of the inter-industry carbon emission transfer are relatively high.

(2) As for dynamic variations, the decoupling effects of industrial carbon emission transfer were optimal during the late stage and the decoupling effects during 2010-2012 were optimal. With regard to the development trends in the three periods of 2005-2007, 2007-2010, and 2010-2012, the number of industries with strong decoupling state increased significantly. This suggests that the economic development level of these industries improved and that the growth rate of carbon emission was lower than that of economic development.

(3) From the optimizing strategies for industrial carbon emission transfer, to better realize the dual goals of industrial economic development and carbon emission reduction, efforts should be focused on further increasing the carbon emission exports, while reducing the carbon emission imports in 11 industries (CMWI and others); furthermore, the carbon emission imports should be increased and the carbon emission exports should be decreased in the three industries of CLII, PPSM, and MPI. Considering the strong decoupling effects of carbon emission transfer of FMTP and the other nine industries, increasing both the carbon emission exports and the imports in these industries will not only promote the economic development of these industries but will also facilitate the realization of their emission reduction goals. In the three industries of MMII, OMW, and WRT, carbon emission transfer predominantly presented strong negative decoupling effects; therefore, seen from the optimizing strategies for carbon emission transfer in these three industries, it is necessary to reduce both carbon emission imports and exports in these three industries in particular.

\section{Acknowledgments}

The authors are grateful to the financial support by the National Natural Science Foundation of China (nos.71473107,71573186, 71673117, 71471076), the MOE (Ministry of Education of China) Youth Fund Project of Humanities and Social Sciences(no. 16YJCZH153), and Jiangsu Qing Lan project.

\section{References}

1. Herry,C.G., Herry,M., Sedlacek,N.,2003.Decoupling economic growth and transport demand case study Austria,10-20.

2. Tapio,P.,2005. Towards a theory of decoupling: degrees of decoupling in the EU and the case of road traffic in Finland between 1970 and 2001. Transport Policy, 12(2),137-151.

3. Lu,I.J., Lin,S.J., Lewis,C.,2007. Decomposition and decoupling effects of carbon dioxide emission from highway transportation in Taiwan, Germany, Japan and South Korea. Energy Policy, 35(6),3226-3235. 
4. Zhao,X., Zhang,X., Shao,S.,2016.Decoupling $\mathrm{CO}_{2}$, emissions and industrial growth in China over 1993-2013: the role of investment. Energy Economics, 60,275-292.

5. Leontief,W.,1970.Environmental repercussions and the economic structure: an input-output approach. The Review of Economics and Statistics , 52 (3), 262-271

6. Sun,L.C.,Wang,Q.W.,Zhang,J.J.,2017.Inter-industri al Carbon Emission Transfers in China: Economic Effect and Optimization Strategy. Ecological Economics, 132,55-62.

7. $\mathrm{Su}, \mathrm{B}$,

Huang,H,Ang,B.W., Zhou,P.,2010.Input-output analysis of $\mathrm{CO}_{2}$ emissions embodied in trade: the effects of sector aggregation. Energy Economics, 32 (1),166-175.

8. Sun,L.C.,Wang,Q.W, hou,P.,Cheng,F.X.,2016.Effects of carbon emission transfer on economic spillover and carbon emission reduction in China.Journal of Cleaner Production, 112(1), 1432-1442.

9. Feng,B.,Wang,X.Q.,2015.Research on carbon decoupling effect and influence factors of provincial construction industry in China[J]. Chinese Population, Resources and Environment, 25(4),28-34. (in Chinese)

10. Guo,C.X.,2010. An analysis of the increase of $\mathrm{CO}_{2}$ emission in China: based on SDA technique.China Industrial Economics,12,47-56. (in Chinese) 